\title{
Evaluation of condensation heat transfer in air-cooled condenser by dominant flow criteria
}

\author{
Yanán Camaraza-Medina ${ }^{1 *}$, Nislan H. Khandy ${ }^{2}$, Ken M. Carlson ${ }^{3}$, Oscar M. Cruz-Fonticiella ${ }^{4}$, Osvaldo F. García-Morales \\ Diamela Reyes-Cabrera ${ }^{5}$ \\ ${ }^{1}$ Center of Energy Studies and Environmental Technology, Universidad Central de Las Villas, Santa Clara, Cuba \\ ${ }^{2}$ Mechanical \& Aerospace Engineering Department, New Mexico State University, NM 88003, USA \\ ${ }^{3}$ Department of Chemical Engineering, University of California, Santa Barbara, CA 93106, USA \\ ${ }^{4}$ Center of Energy Studies and Environmental Technology, Universidad Central de Las Villas, Santa Clara, Cuba \\ ${ }^{5}$ Technical Sciences Faculty, Universidad de Matanzas, Matanzas, Cuba
}

Corresponding Author Email: ycamaraza1980@yahoo.com

https://doi.org/10.18280/mmep.050204

Received: 24 April 2018

Accepted: 26 May 2018

\section{Keywords:}

flow criteria, condensation, deviation, heat transfer

\begin{abstract}
In this paper, a modification to the dominant flow criteria is presented for the study of heat transfer by confined condensation in Air Cooled Condenser (ACC) systems. The new methodology combines in one single procedure the analysis, which with the current methods requires tedious grouping processes. A new proposal reduces the average error by computing $22 \%$ in $88.7 \%$ of the available samples and includes the shear stress produced by the steam drag when it flows at speeds greater than $40 \mathrm{~m} / \mathrm{s}$. New method is also valid for a vapor quality located between 0.9 and steam flows between 3 and $590 \mathrm{~kg} /(\mathrm{m} 2 / \mathrm{s}-1)$, values for the Reynolds number for the liquid portion between 660 and 58540 and the Reynolds number for the vapor portion located between 1320 and 333 120, internal equivalent diameters of the tubes comprised between 7.4 to $49 \mathrm{~mm}$.
\end{abstract}

\section{INTRODUCTION}

The totality of the condensation processes found in the application of dry condensation systems (ACC) to power plants are related to condensation on the interior surfaces of horizontal or vertical pipes. The analysis of the heat transfer of condensation inside pipes is complicated by the fact that the speed of the steam and the rapidity of the accumulation of liquid on the walls of the tubes strongly influence it [1-2]. The volume of steam is limited by the walls inside the tubes. A large amount of steam was condensed in the tubes because it was considerable long. The steam flows inside the tube and condenses as it moves along it. The steam flow is oriented and its speed can be very high (more than $100 \mathrm{~m} / \mathrm{s}$ ). The friction at the vapor-condensate interface can therefore be considerable.

If the direction of the steam flow coincides with that of the condensate flowing by gravity. The friction produces an acceleration of the latter, thinning the film and increasing the surface heat transfer coefficient. If the steam flows in the opposite direction to that of the condensate, the film can be decelerated, its thickness increased, and the intensity of surface heat transmission reduced. An increase in the steam speed can cause the drag of the film and its partial separation from the wall. Which produces an increase in the heat transmission, therefore inside the pipes. This can depend on the dynamic effect of the steam on the condensate film [3-4].

This effect manifests itself in different ways, depending on the direction of gravity and friction, which is determined not only by the position of the tube in space, but by the direction of the steam flow, up or down, in inclined or vertical tubes. In the available literature and consulted due to the complexity of the problem in question the process of heat transfer by condensation in ACC systems is divided into four intervals or study areas. Which becomes somewhat cumbersome, especially in multiple systems of panels ACC, because the lengths of the tubes are already appreciable and therefore the simultaneity of two or more zones in the same system is frequent. This drawback is currently a limiting factor in modern power plants, since the output, powers are high and therefore, the heat volumes to be rejected in these also take appreciable values, which requires the combined operation of multiple systems of ACC panels. At present, there is no single methodology to solve these limitations and errors in the results obtained are lower than those computed with the use of currently available methods $(25 \%)$. For this reason, the authors are imposed as fundamental task in the present investigation to develop in a compact way a methodology that includes all of these effects in the process of heat transfer by condensation, and that is valid in the four known regions and whose average error is less than 25\% [3-4].

For them, available experimental quantities obtained from direct communication with specialists of recognized prestige in the area of action at international level, as well as values reported in works elaborated with intentions similar to the present one.

\section{METHODS AND VALIDATION}

\subsection{Criteria for differentiation of the dominant condensation flow}

In a previous work, the authors developed a methodology for obtaining the average heat transfer coefficient for the condensation of water vapor inside ACC systems, considering 
that for this purpose the steam has a negligible speed. This expression was obtained by the author and his collaborators and is given by [5]:

$N u=0.923 \sqrt[4]{d^{3} \frac{\left(\rho_{L}-\rho_{V}\right) g \sin \phi\left(r_{L V}+\frac{3}{8} C p_{L}\left(T_{S a t}-T_{p}\right)\right)}{v_{L} \lambda_{L}\left(T_{S a t}-T_{p}\right) d}}$

However, the different operative situations make the criterion of dominant flow inside the ACC tubes variable, which is why it is necessary to determine which is the dominant criterion for later proceeding to the case analysis. A criterion used to solve this problem is the one given by Martinelli-Lockhart [6], it is based on the combination of two dimensionless criteria which are:

Martinelli's parameter:

$W=\left(\frac{1-x}{x}\right)^{0.9} \sqrt{\frac{\rho_{V}}{\rho_{L}}}\left(\frac{\mu_{V}}{\mu_{L}}\right)^{-0.1}$

Dimensionless speed:

$J=\frac{x G}{\sqrt{g \rho_{V}\left(\rho_{L}-\rho_{V}\right) d_{I}}}$

The results obtained through the application of relations (2) and (3) make it possible to identify the dominant flow criterion, using the identifiers provided in table 1 for this purpose.

As can be seen in table 1, the condensation process of water vapor inside the pipes of an ACC system is extremely complex, since several zones are formed from the steam inlet to the formation of the sub-cooled liquid [7].

It would be convenient to have initially the fundamental characteristics of each flow area as well as the most accepted and widespread expression in the literature for the determination of the average coefficient of heat transfer in it.

Table 1. Validity ranges for the dominant flow condensation criteria in ACC systems

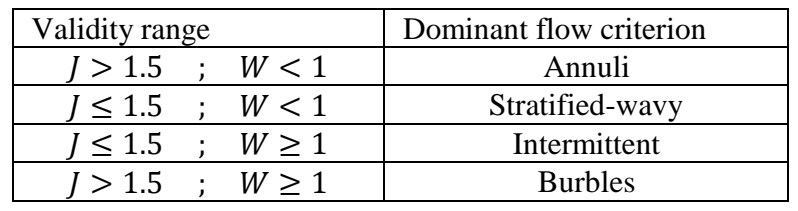

Stratified-wavyflow: when the steam has a medium or low velocity, the convective heat transfer in the stratified liquid that is stored in the bottom of the tube may not be negligible; secondly, the axial steam flow may interfere in the speed and heat transfer of the film around the tube wall. In the work [8] this zone was studied in detail, being further reported that the stratified-corrugated flow regime is present inside a tube when it is fulfilled that $G<500 \mathrm{~kg} / \mathrm{m}^{2} \mathrm{~s}, V>0.5 \mathrm{~m} / \mathrm{s}$ and $\mathrm{Fr}^{*}<20$.

The term $\mathrm{Fr}^{*}$ is the modified Froude number, which is given by [9]:

$F r^{*}=A\left(\frac{\operatorname{Re}_{L}^{B}}{\sqrt{G a}}\right)\left(\frac{1+1,09 W^{0.039}}{W}\right)^{1.5}$
In Equation (4) the Reynolds number for the liquid state $R e_{L}$ and the Galileo number Gaare determined by the following expressions

$$
\begin{aligned}
& \operatorname{Re}_{L}=\frac{G(1-x) d_{I}}{\mu_{L}} \\
& G a=\frac{\rho_{L}\left(\rho_{L}-\rho_{V}\right) g d_{I}^{3}}{\mu_{L}^{2}}
\end{aligned}
$$

Finally the numerical value of the constants $A$ and $B$ present in the expression (4) are dependent on the Reynolds number for the liquid state $R e_{L}$. This dependence is shown in table 2 .

Table 2. Values of constants $A$ and $B$ in equation (4)

\begin{tabular}{|c|c|c|}
\hline Applicability range & $\mathrm{A}$ & $\mathrm{B}$ \\
\hline $\operatorname{Re}_{L} \leq 1250$ & 0.025 & 1.59 \\
\hline $\operatorname{Re}_{L}>1250$ & 1.26 & 1.04 \\
\hline
\end{tabular}

The average heat transfer coefficient in this area is dependent on three factors, which are:

1- Heat transfer coefficient for the steam portion

$N u_{P}=\frac{0.23\left(\frac{G d_{i}}{\mu_{V}}\right)^{0.12}}{1+1.11 \cdot W^{0.58}}\left(\frac{G a \cdot \operatorname{Pr}_{L}\left(r_{L V}\right)}{C p_{L}\left(T_{S a t}-T_{P}\right)}\right)^{0.5}$

2- Sweeping angle of the steam portion (see figure 1)

$\left(1-\frac{\theta}{\pi}\right)=\cos ^{-1}\left(\frac{2\left[1+\frac{1-x}{x}\left(\frac{\rho_{V}}{\rho_{L}}\right)^{2 / 3}\right]-1}{\pi}\right)$

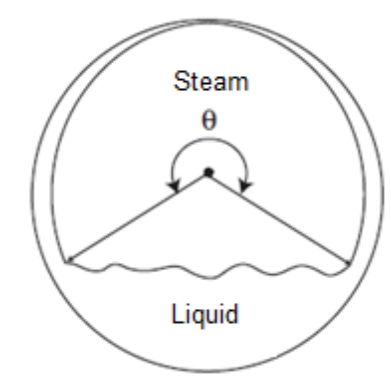

Figure 1. Sweeping angle of the steam portion

3- Heat transfer coefficient for the liquid portion

$N u_{F}=0.0195 \operatorname{Re}_{L}^{0.8} \operatorname{Pr}_{L}^{0.4} \sqrt{1.376+\frac{C}{W^{D}}}$

Numerical value of the constants C and D present in the expression (9) are shown in table 3. 
Table 3. Values of constants C and D in equation (9)

\begin{tabular}{|l|l|l|}
\hline Range & {$\left[\frac{\left(G / \rho_{L}\right)^{2}}{g d_{I}}\right] \leq 0.7$} & {$\left[\frac{\left(G / \rho_{L}\right)^{2}}{g d_{I}}\right]>0.7$} \\
\hline$C$ & $4.172+5.48 \cdot\left[\frac{\left(G / \rho_{L}\right)^{2}}{g d_{I}}\right]-1.564\left[\frac{\left(G / \rho_{L}\right)^{2}}{g d_{I}}\right]^{2}$ & 7.242 \\
\hline$D$ & $1.773-0.169 \cdot\left[\frac{\left(G / \rho_{L}\right)^{2}}{g d_{I}}\right]$ & 1.655 \\
\hline
\end{tabular}

The results obtained with the use of equations (7), (8) and (9) are combined to obtain the total heat transfer coefficient by the following expression [10]:

$$
N u=N u_{P}+\left(1-\frac{\theta}{\pi}\right) N u_{F}
$$

Expression (10) is is correlated with 383 experimental available, finding that it is adjusted with an average error of $15 \%$ in the $79.4 \%$ experimental data available.

Annuliflow: This type of flow occurs when the speed of the steam is high, so that the gravitational effects can be ignored, while the condensate is deposited in a thin annular layer around the tube wall, without the presence of stratification. A significant part of most condensers operates under the conditions of this flow regime.

Of all the known models, the Chato's equation has the greatest acceptance and use in the ACC systems that operate in the annular zone. This is given by:

$N u=0.023 \operatorname{Re}_{L}^{0.8} \operatorname{Pr}_{L}^{0.4}\left[1+\frac{2.22}{W^{0.89}}\right]^{0.8}$

In this zone, the laminar flow models predict low values of the average heat transfer coefficient, so turbulent models should be used in this case. Chato's model (11) is expressed in function of the local number of Nusselt, therefore they must be integrated over the entire length of the tube in function of finding the average coefficient of heat transfer, so that [11-13]:

$$
\alpha=\frac{1}{L} \int_{0}^{L} \alpha(z) d z
$$

A drawback in equation (12) lies in the fact that the dependence of the steam quality xon the axial positionzmust be known. This is usually solved by subdividing the total length into a number of sub-elements of length $\Delta z$ from the beginning of the condensate process, i.e. from inlet to outlet of the tube, using the local coefficient of heat transfer for each sub-element (normally 4 elements are taken for achieve a medium precision). Assuming that the steam quality varies linearly, which unfortunately does not happen in many cases, then the heat transfer coefficient can be determined approximately by taking the steam quality as $x=0.5$ in the expressions for the determination of the local heat transfer coefficient.

An approximate solution for this problem was proposed by Mishra [14], who reports from a total of 813 measurements made in the laboratory, that the behavior of the variation of the quality of the steam presents a parabolic behavior whenever it is fulfilled in the tube entry that $x<0.95$. This curve has a average deviation of $15 \%$, being described by the following expression:

$x^{\prime \prime}=0.43\left(\frac{l}{l_{T}}\right)^{2}-1.341\left(\frac{l}{l_{T}}\right)^{2}+0.011+x$

Intermittent flow: It occurs during condensation in tubes when the steam velocity is too low, (less than $0.5 \mathrm{~m} / \mathrm{s}$ ) flow can be dominated by gravitational effects, and then forces and stratification of the condensate can occur, that is, the condensate forms a thin film in the wall of the upper portion of the tube and drains by the periphery of this by the effect of gravitational forces towards the bottom of the tube where it joins the axially flowing condensate due to the shear stress of the fluid stream.

In the known literature there are not many works on this type of condensation criterion, and in all cases the most recommended expression is that obtained by Shah, which is given by [15-16]:

$$
\bar{\alpha}=0.728 \frac{\left(\frac{\lambda_{L}^{3} \rho_{L}\left(\rho_{L}-\rho_{V}\right) g \cdot\left(r_{L V}\right)}{\mu_{L}\left(T_{S a t}-T_{P}\right) d_{I}}\right)^{1 / 4}}{\left[1+\frac{1-x}{x}\left(\frac{\rho_{V}}{\rho_{L}}\right)^{2 / 3}\right]^{0.75}}
$$

The expression (14) correlates moderately with available experimental data, since in a total 274 test an average deviation of $28 \%$ was found in $80.1 \%$ of the samples.

Burbles Flow: This regime of condensate flow appears when inside the tube and most of its content is subcooled liquid. However there are still individual bubbles, which collapse and are controlled both by the inertia of the liquid and by heat transfer. Depending fundamentally on the degree of sub cooling of the liquid. One of the most well-known and recommended expressions for this type of flow is the JasterKosky equation, which is given by [18-20]:

$$
N u=\frac{\alpha d_{I}}{\lambda_{F}}=\frac{0.728}{\left[1+\frac{1-x}{x}\left(\frac{\rho_{V}}{\rho_{L}}\right)^{2 / 3}\right]}\left(\frac{\rho_{L}\left(\rho_{L}-\rho_{V}\right) g\left(r_{L V}+\frac{3}{8} C p_{L}\left(T_{\text {Sat }}-T_{P}\right)\right)}{\lambda_{L} \mu_{L}\left(T_{\text {Sat }}-T_{P}\right) d_{I}}\right)^{1 / 4}
$$

Expression (15) correlates moderately with available experimental data, because in 104 tests an average deviation of $35 \%$ was found in $78.1 \%$ of the samples [21-24].

\subsection{Experimental validation of a single model for condensation in ACC systems}

As was shown in the previous section, the study of the process of heat transfer by condensation in ACC systems becomes complex due to the number of elements to be considered, as well as the high number of expressions involved in the study.

It would be reasonable to have a single expression that allows to evaluate the heat transfer coefficient in any of the zones and whose results are close to the precision environment obtained with the use of the current methods, which were not developed for the exclusive use in ACC systems. Main reason for the failure in many cases of the methods available today. 
Access to an appreciable group of available experimental data is taken as a starting point for the present study. The correlation of the available experimental quantities allows having a unique function for the evaluation of condensation heat transfer coefficient, which responds to the following expression [25-29]:

for $0.9 \leq x \leq 0.95 \rightarrow \alpha_{T}=C_{1} \cdot \frac{\left\lfloor 1-0,03 \cdot\left(P_{b a c k}-5\right)^{0,71}\right\rfloor \cdot m^{0,8}}{0,19 \cdot d^{1,8}}$

for $0.95<x \leq 1 \rightarrow \alpha_{T}=C_{2} \frac{\left[1-0.028 \cdot\left(P_{b a c k}-5\right)^{0,71}\right] \cdot m^{0,8}}{0.19 \cdot d^{1,8}}$

where:

$$
\begin{aligned}
& \text { for } 0.9 \leq x \leq 0.95 \rightarrow C_{1}=0.25 \operatorname{Ln}(x)+1.026 \\
& \text { for } 0.95<x \leq 1 \rightarrow C_{2}=-0.8 \operatorname{Ln}(x)+0.972
\end{aligned}
$$

The experimental data used in the generalization and development of the expression (16) and (17) are provided in table 4. Figure 2 shows the correlation of experimental data. In the $y$-axis is plotted the decimal logarithm of the quotient between film coefficients calculated with the use of equations (16) and (17) while the Shah parameter is plotted along the Xaxis, which is given by

$$
Z=\left(\frac{1-x}{x}\right)^{0.8} \operatorname{Pr}_{L}^{0.4}
$$

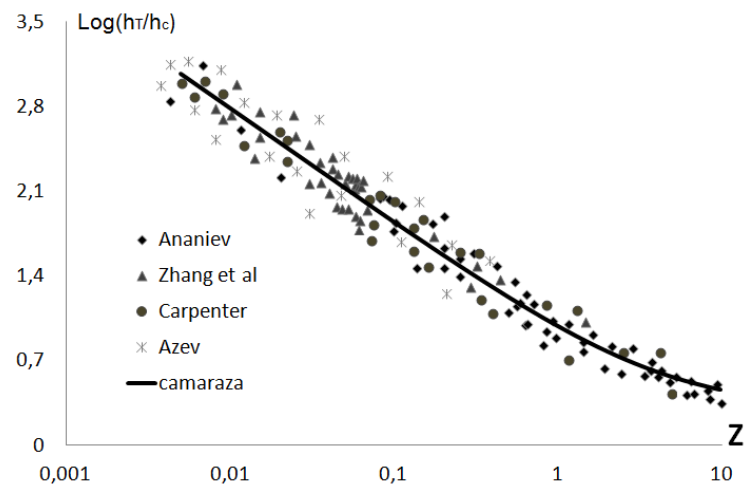

Figure 2. Comparison of condensing data in horizontal tubes with the proposed correlation, Equation (20)

\section{TRAWL ANALYSIS CAUSED BY HIGH VAPOR VELOCITIES.}

The expressions given above are valid only if the steam drag is negligible or insignificant. This assumption is appropriate in the ACC when the steam velocity does not exceed $50 \mathrm{~m} / \mathrm{s}$, but already for higher speeds of the steam flow the effect of the drag on the liquid film cannot be ignored.

To take into account the effect of the drag on the liquid film, it is necessary to include the influence of shear stress on the surface of the liquid, that is:

$$
\tau_{S}=\frac{C_{W} \rho_{V} V_{E}^{2}}{2}
$$

Two apparently appropriate expressions could be the Blasius solutions for the laminar boundary layer and the boundary layer turbulent. However there is an additional problem, and that is that these two expressions are only valid for a waterproof wall, while the surface the liquid has a normal component of speed due to condensation. In many texts of fluid mechanics it would be said that in this case there is presence of suction on the surface. In typical condensation problems the suction speed of the suction is relatively large and causes the thickness of the boundary layer to become almost constant very close to the initial edge, and the steam velocity is, in essence, only a function of $V_{E}$

This can be partially solved if the model elaborated by Couette for laminar flow is used, it can be used to determine the shear forces acting on a boundary layer subject to a strong suction effort (see figure 3 ).

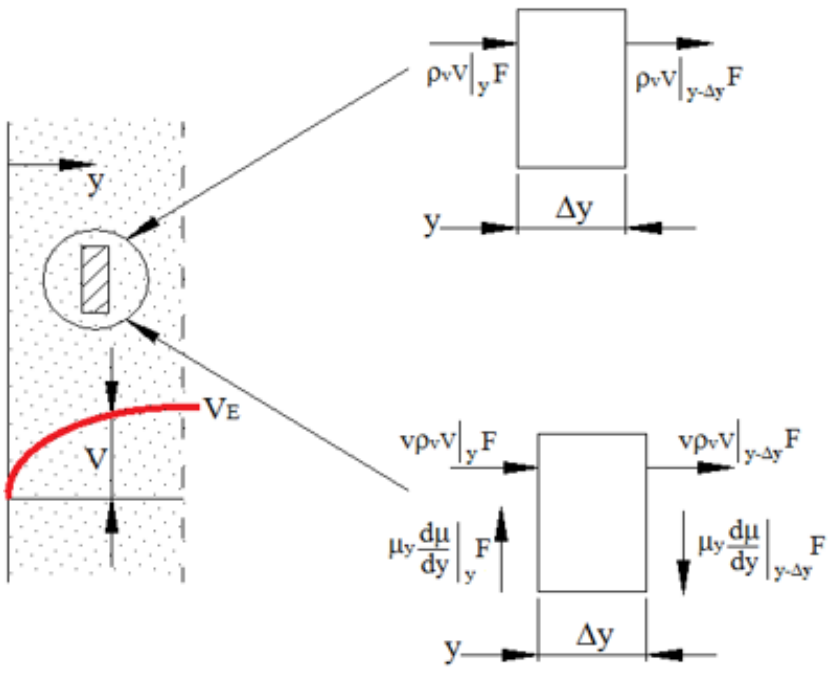

Figure 3. Model problem and elementary volumes employed

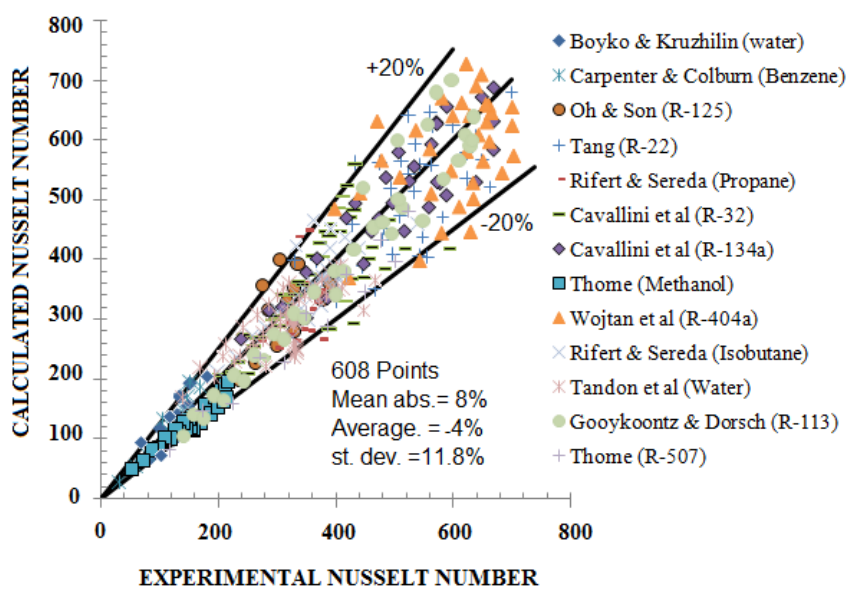

Figure 4. Application of the model to vertical and inclined tubes data reported by several authors

After an appreciable group of mathematical transformations, we arrive at a conclusive expression that allows us to determine the coefficient of transfer of lime by condensation in air-cooled systems when the effect of the steam drag on the surface of the liquid is taken into account. This expression is described by [11]: 
$\alpha=\left[\frac{\lambda_{L}^{2} V_{E}}{8 v_{L} x}\left\{1+\left(\frac{16 \operatorname{Pr}_{L}}{J a} \frac{g x}{V_{E}^{2}}\right)^{0,5}\right\}\right]^{0,5}$

Therefore, when the steam velocity in an ACC system is higher than $40 \mathrm{~m} / \mathrm{s}$, it is necessary to establish a product between the results obtained by using equation (16) and (17) with Equation (22), to obtain the heat transfer coefficient [3134].

Experimental $N u_{E}$ and calculated Nusselt numbers $N u_{T}$, obtained by means of the present model, are compared in the following diagrams. Figures 4 show the results relative to the vertical and inclined tubes, while in the figure 5 show horizontal tubes.

Table 4. Summary of the experimental quantities used

\begin{tabular}{|c|c|c|c|c|c|c|c|c|c|}
\hline Source & $\begin{array}{c}\text { Number of } \\
\text { experimental data }\end{array}$ & Fluid & $\begin{array}{l}\text { Diameter } \\
(\mathrm{mm})\end{array}$ & $\begin{array}{c}G \\
\left(\mathrm{~kg} / \mathrm{m}^{2} \mathrm{~s}\right) \\
\end{array}$ & $x$ & $\operatorname{Re}_{L}$ & $\operatorname{ReV}_{V}$ & $p_{R}$ & $\begin{array}{c}\text { Deviation } \\
{[\%]} \\
\end{array}$ \\
\hline Jakob et al. (1932) & 31 & Water & 40.0 & $\begin{array}{l}24 \\
48 \\
\end{array}$ & $\begin{array}{l}0.96 \\
0.88 \\
\end{array}$ & $\begin{array}{l}3427 \\
6854 \\
\end{array}$ & $\begin{array}{c}79438 \\
158870 \\
\end{array}$ & 0.0046 & $\begin{array}{l}13.7 \\
11.4 \\
\end{array}$ \\
\hline $\begin{array}{c}\text { Al-Shmmari et al. } \\
(2004)\end{array}$ & 9 & Water & 28.2 & 3 & $\begin{array}{c}0.97 \\
0.9 \\
\end{array}$ & 173 & 8210 & 0.0008 & $\begin{array}{c}12.1 \\
9.7\end{array}$ \\
\hline Khun et al. (1997) & 11 & Water & 47.5 & 10 & $\begin{array}{c}0.94 \\
0.9 \\
\end{array}$ & 2554 & 32642 & 0.023 & $\begin{array}{l}16.2 \\
-6.1 \\
\end{array}$ \\
\hline $\begin{array}{c}\text { Borishankiy et al. } \\
(1976)\end{array}$ & 34 & Water & $\begin{array}{l}10.0 \\
19.3 \\
\end{array}$ & $\begin{array}{c}12 \\
590 \\
\end{array}$ & 0.92 & $\begin{array}{c}763 \\
58540 \\
\end{array}$ & $\begin{array}{c}8284 \\
333120 \\
\end{array}$ & $\begin{array}{l}0.036 \\
0.308 \\
\end{array}$ & $\begin{array}{l}12.7 \\
-1.3 \\
\end{array}$ \\
\hline $\begin{array}{c}\text { Lee and Kim } \\
(2008)\end{array}$ & 15 & Water & 12.0 & $\begin{array}{l}27 \\
45 \\
\end{array}$ & $\begin{array}{l}0.98 \\
0.95 \\
\end{array}$ & $\begin{array}{l}1183 \\
1944 \\
\end{array}$ & $\begin{array}{l}27421 \\
45071 \\
\end{array}$ & 0.0046 & $\begin{array}{c}16.9 \\
8.1 \\
\end{array}$ \\
\hline $\begin{array}{c}\text { Gooykoontz et al. } \\
\text { (1967) }\end{array}$ & 26 & Water & 7.4 & $\begin{array}{l}131 \\
264 \\
\end{array}$ & $\begin{array}{c}0.99 \\
0.9 \\
\end{array}$ & $\begin{array}{l}3827 \\
6567 \\
\end{array}$ & $\begin{array}{c}78853 \\
167186 \\
\end{array}$ & $\begin{array}{c}0.002 \\
0.0062 \\
\end{array}$ & $\begin{array}{l}1.8 \\
2.5 \\
\end{array}$ \\
\hline $\begin{array}{c}\text { Gooykoontz et al. } \\
\text { (1967) }\end{array}$ & 19 & Water & 15.9 & $\begin{array}{l}22 \\
74 \\
\end{array}$ & $\begin{array}{l}0.99 \\
0.91 \\
\end{array}$ & $\begin{array}{c}660 \\
2300 \\
\end{array}$ & $\begin{array}{l}1320 \\
4560 \\
\end{array}$ & $\begin{array}{l}0.005 \\
0.017 \\
\end{array}$ & $\begin{array}{c}17.6 \\
8.4\end{array}$ \\
\hline $\begin{array}{c}\text { Blageti - Slunder } \\
(1978)\end{array}$ & 21 & Water & 30.0 & $\begin{array}{c}4 \\
69 \\
\end{array}$ & $\begin{array}{l}0.99 \\
0.94 \\
\end{array}$ & $\begin{array}{c}408 \\
7474 \\
\end{array}$ & $\begin{array}{c}9173 \\
252428 \\
\end{array}$ & 0.0046 & $\begin{array}{l}22.9 \\
-0.3 \\
\end{array}$ \\
\hline Annaniev (1961) & 63 & Water & 8.0 & $\begin{array}{c}38 \\
160 \\
\end{array}$ & $\begin{array}{l}0.99 \\
0.91 \\
\end{array}$ & 10254324 & $\begin{array}{l}21158 \\
89085 \\
\end{array}$ & $\begin{array}{l}0.031 \\
0.004 \\
\end{array}$ & $\begin{array}{l}25.3 \\
19.4 \\
\end{array}$ \\
\hline Carpenter (1948) & 12 & Water & 11.6 & $\begin{array}{c}16 \\
140 \\
\end{array}$ & $\begin{array}{l}0.97 \\
0.95 \\
\end{array}$ & $\begin{array}{c}692 \\
5934 \\
\end{array}$ & 15686.134474 & 0.0046 & $\begin{array}{l}21.2 \\
12.8 \\
\end{array}$ \\
\hline Annaniev (1961) & 68 & Water & 8.0 & $\begin{array}{c}38 \\
160\end{array}$ & $\begin{array}{l}0.99 \\
0.91\end{array}$ & $\begin{array}{l}1025 \\
4324 \\
\end{array}$ & $\begin{array}{l}21158 \\
89085 \\
\end{array}$ & $\begin{array}{l}0.051 \\
0.004\end{array}$ & $\begin{array}{l}25.3 \\
19.5\end{array}$ \\
\hline Varma (1977) & 20 & Water & 49.0 & 12 & $\begin{array}{l}0.95 \\
0.89 \\
\end{array}$ & 1808 & 54415 & 0.0023 & $\begin{array}{l}6.2 \\
1.5 \\
\end{array}$ \\
\hline $\begin{array}{c}\text { Gooykoontz et al } \\
(1967)\end{array}$ & 20 & Water & 15.9 & $\begin{array}{l}20 \\
74 \\
\end{array}$ & $\begin{array}{c}0.99 \\
0.9\end{array}$ & $\begin{array}{c}660 \\
2800 \\
\end{array}$ & $\begin{array}{l}1320 \\
4960 \\
\end{array}$ & $\begin{array}{l}0.005 \\
0.017 \\
\end{array}$ & $\begin{array}{c}17.4 \\
8.1\end{array}$ \\
\hline TOTAL & 349 & & $\begin{array}{c}7.4 \\
49.0 \\
\end{array}$ & $\begin{array}{c}3 \\
590 \\
\end{array}$ & $\begin{array}{l}0.99 \\
0.88 \\
\end{array}$ & $\begin{array}{c}660 \\
58540 \\
\end{array}$ & $\begin{array}{c}1320 \\
333120 \\
\end{array}$ & $\begin{array}{c}0.0008 \\
0.031\end{array}$ & $\begin{array}{c}16.6 \\
7.5 \\
\end{array}$ \\
\hline
\end{tabular}

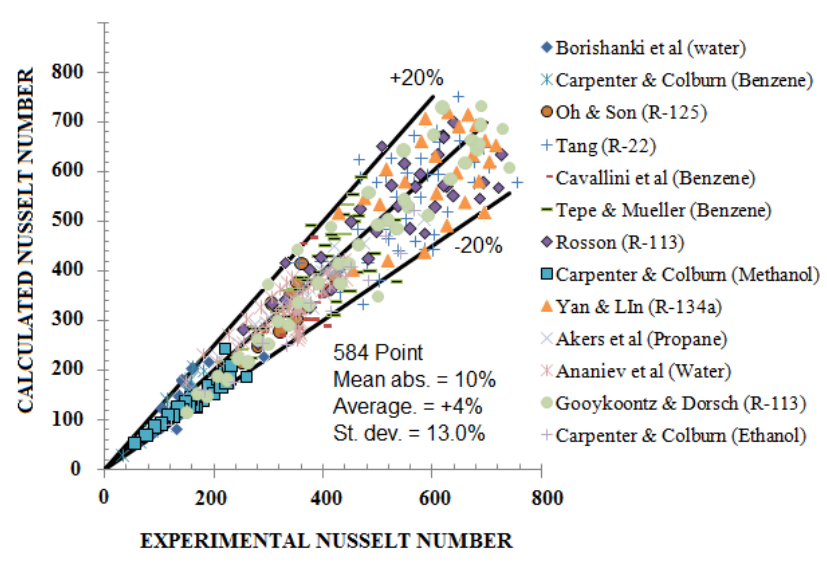

Figure 5. Application of the model to horizontal tubes data reported by several authors

\section{CONCLUSIONS}

A new model has been developed that unites in a unitary procedure the tedious established procedures for the determination of the average coefficient of heat transfer by means of the dominant flow criterion techniques. The new proposal includes the effect of steam drag when it exceeds the critical speed inside the ACC, and the results obtained with its use compute an average error of $22 \%$ in $88.7 \%$ of the available samples. The results obtained agree with the initial criterion that supported the investigation, considering that the objectives of the same were fulfilled. The new method is also valid for a steam quality located between 0.9 and one, for steam flows between 3 and $590 \mathrm{~kg} /\left(\mathrm{m}^{2} \cdot \mathrm{s}^{-1}\right)$, values for the Reynolds number for the liquid portion between 660 and 58 540 and the Reynolds number for the vapor portion located between 1320 and 333 120, internal equivalent diameters of the tubes comprised between 7.4 to $49 \mathrm{~mm}$.

\section{ACKNOWLEDGMENT}

This work was supported by Doctoral Research Program of Universidad Central de las Villas, Cuba.

\section{REFERENCES}

[1] Dorao CA, Fernandhino M. (2017). Dominant dimensionless groups controlling heat transfer 
coefficient during flow condensation inside pipes. International Journal of Heat and Mass Transfer 112: 465-479.

https://doi.org/10.1016/j.ijheatmasstransfer.2017.04.104

[2] Boyko LD, Kruzhilin GN. (1967). Heat transfer and hydraulic resistance during condensation of steam in a horizontal tube and in a bundle of tubes. International Journal of Heat and Mass Transfer 10(3): 361-373. https://doi.org/10.1016/0017-9310(67)90152-4.

[3] Kim SM. Mudawar I. (2013). Universal approach to predicting heat transfer coefficient for condensing mini/micro-channel flow. International Journal of Heat and Mass Transfer 56(1-2): 238-250.

http://dx.doi.org/10.1016/j.ijheatmasstransfer.2012.09.0 32

[4] Zhang H, Fang X, Shang H, Chen W. (2015). Flow condensation heat transfer correlations. International Journal of Refrigeration 59: 102-114. http://dx.doi.org/10.1016/j.ijrefrig.2015.07.013

[5] Shah MM. (1979). A general correlation for heat transfer during film condensation inside pipes. International Journal of Heat and Mass Transfer 22(4): 547-556. https://doi.org/10.1016/0017-9310(79)90058-9

[6] Rosson F. (1957). Heat transfer during condensation inside a horizontal tube. Ph.D. dissertation. Rice University, Houston, USA.

[7] Tandon TN, Varma HK, Gupta CP. (1995). Heat transfer during forced convection condensation inside horizontal tube. International Journal Refrigeration 18(3): 210-214. https://doi.org/10.1016/0140-7007(95)90316-R

[8] Dobson MK, Chato JC. (1998). Condensation in smooth horizontal tubes. Journal Heat Transfer 120(1): 193-213. http://dx.doi.org/10.1115/1.2830043

[9] Cavallini A, Col DD, Doretti L, Matkovic M, Rossetto L, Zilio C, Censi G. (2006). Condensation in horizontal smooth tubes: A new heat transfer model for heat exchanger design. Heat Transfer Engineering 27(8): 3138. https://doi.org/10.1080/01457630600793970

[10] Bohdal T, Charun H, Sikora M. (2012). Heat transfer during condensation of refrigerants in tubular minichannels. Archives of Thermodynamics 33(2): 3-22. http://dx.doi.org/10.2478/v10173-012-0008-x

[11] Camaraza Y. (2017). Introducción a la termotransferencia. Ed. Universitaria, La Habana, Cuba.

[12] Camaraza Y, Khandy NH, Cruz-Fonticiella OM, Garcia OF. (2017). Abstract of heat transfer coefficient modelation in single-phase systems inside pipes. Mathematical Modelling of Engineering Problems 4(3): 132-136. https://doi.org/10.18280/mmep.040303

[13] Camaraza Y, Cruz-Fonticiella OM, Garcia OF. (2018). Obtención de un modelo para la determinación del coeficiente medio de transferencia de calor por condensación en sistemas ACC. Tecnología Química 38(1): http://scielo.sld.cu/pdf/rtq/v38n1/rtq15118.pdf

[14] Lee H, Yoon J, Kim Y, Bansal PK. (2006). Condensing heat transfer and pressure drop characteristics of hydrocarbon refrigerants. International Journal of Heat and Mass Transfer 49: 1922-1927. https://doi.org/10.1016/j.ijheatmasstransfer.2005.11.008

[15] Yan Y, Lin T. (1999). Condensation heat transfer and pressure drop of refrigerant R-134a in a small pipe. International Journal of Heat and Mass Transfer 42: 697708. https://doi.org/10.1016/S0017-9310(98)00195-1
[16] Akers WW, Deans HA, Crosser OK. (1959). Condensing heat transfer within horizontal tubes. Chemical Engineering Progress Symposium Series 55(29): 171176.

[17] Lemmon EW, Huber ML, McLinden MO. (2013) NIST Reference Fluid Thermodynamic and Transport Properties REFPROP, Tech. Rep.

[18] Tang CC. (2011). A study of heat transfer in non-boiling two-phase gas-liquid flow in tubes for horizontal, slightly inclined, and vertical orientations. Ph.D. dissertation. Oklahoma State University Publishing.

[19] Mollamahmutoglu M. (2012). Study of isothermal pressure drop and non-boiling heat transfer in vertical downward two phase flow. Ms. dissertation. Oklahoma State University Publishing.

[20] Cavallini A, Censi G, Doretti L, Longo GA, Rossetto L, Zilio C. (2003). Condensation inside and outside smooth and enhanced tubes - a review of recent research. International Journal of Refrigeration 26(4): 373-392. http://dx.doi.org/10.1016/S0140-7007(02)00150-0

[21] Wojtan L, Ursenbacher T, Thome JR. (2005). Investigation of flow boiling in horizontal tubes: Part II. Development of a new heat transfer model for stratifiedwavy, dryout and mist flow regimes. International Journal of Heat and Mass Transfer 48(14): 2970-2985. https://doi.org/10.1016/j.ijheatmasstransfer.2004.12.013

[22] Rifert VG, Sereda VV. (2015). Condensation inside Smooth horizontal tubes: Part 1. Survey of the methods of heat-exchange prediction. Thermal Science 19(5): 1769-1789. https://doi.org/10.2298/TSCI140522036R

[23] Thome JR. (2005). Condensation in plain horizontal tubes: recent advances in modelling of heat transfer to pure fluids and mixtures. Journal of the Brazilian Society of Mechanical Sciences and Engineering 27(1): 23-30. http://dx.doi.org/10.1590/S1678-58782005000100002

[24] Cttani L, Bozzoli F, Raineri S. (2017). Experimental study of the transitional flow regime in coiled tubes by the estimation of local convective heat transfer coefficient. International Journal of Heat and Mass Transfer 112: 825-836. https://doi.org/10.1016/j.ijheatmasstransfer.2017.05.003

[25] Bhagwat SM, Ghajar AJ. ((2016). Experimental investigation of non-boiling gas-liquid two phase flow in upward inclined tubes. Experimental Thermal and Fluid Science 79: 301-318. https://doi.org/10.1016/j.expthermflusci.2016.08.004

[26] Derby M, Joon H, Peles Y, Jensen MK. (2011). Condensation heat transfer in square, triangular, and semi-circular mini-channels. International Journal of Heat and Mass Transfer 55(3): 187-197. https://doi.org/10.1016/j.ijheatmasstransfer.2011.09.002

[27] Nasser I, Duwairi HM. (2016). Thermal dispersion effects on convection heat transfer in porous media with viscous dissipation. International Journal of Heat and Technology 34(2): 207-212. http://doi.org/10.18280/ijht.340208

[28] Pourmahmoud N, Abbaszadeh M, Rashidzadeh M. (2016). Numerical simulation of effect of shell heat transfer on the vortex tube performance. International Journal of Heat and Technology 34(2): 293-301. http://doi.org/10.18280/ijht.340220

[29] Zhang ZY, Yang JG. (2015). The effect of face-air velocity distribution on heat transfer performance of aircooled condensers. International Journal of Heat and 

Technology
33(1):
http://doi.org/10.18280/ijht.330108

[30] Zhan NY, Xu Y, Wang ZY. (2015). Research on heattransfer and three-dimensional characteristics of natural convection in a small cavity with heat sources. International Journal of Heat and Technology 33(3): 5966. http://doi.org/10.18280/ijht.330308

[31] Priyam A, Chand P. (2017). Heat transfer and pressure drop characteristics of wavy fin solar air heater. International Journal of Heat and Technology 35(4): 1015-1022.

[32] Kezzar M, Tabet I, Chieul M, Nafir N, Khentout A. (2018). Analytical investigation of heat transfer of solar air collector by Adomian decomposition method, Mathematical Modelling of Engineering Problems 5(1):40-45, DOI: https://doi.org /10.18280/mmep.050106

[33] Alam MS, Islam T, Uddin MJ. (2016). Mathematical modelling for heat transfer of a micropolar fluid along a permeable stretching/shrinking wedge with heat generation/absorption. Mathematical Modelling of Engineering Problems 3(1): 1-9. https://doi.org/10.18280/mmep.030101

[34] Zhang W, Du X, Yang L, Yang Y. (2016). Research on performance of finned tube bundles of indirect air-cooled heat exchangers. Mathematical Modelling of Engineering Problems 3(1): 47-51. https://doi.org/10.18280/mmep.030108

\section{NOMENCLATURE}

$\begin{array}{ll}\mathrm{G} & \text { Mass flux, } \mathrm{kg} \cdot \mathrm{m}^{-2} \cdot \mathrm{s}^{-1} \\ m & \text { Steam rate, } \mathrm{kg} \cdot \mathrm{s}-1 \\ P_{\text {back }} & \text { Steam pressure, } \mathrm{kPa} \\ \mathrm{Cp} & \text { Specific heat, } \mathrm{J} \cdot \mathrm{kg}^{-1} \cdot \mathrm{K}^{-1}\end{array}$

d Inner equivalent tube diameter, $\mathrm{m}$

g gravitational acceleration, $\mathrm{m} . \mathrm{s}^{-2}$

Re Reynolds number

$\mathrm{Nu} \quad$ Nusselt number

Ga Galileo Number

Ja Jakob Number

Pr Prandtl number

$\operatorname{Pr}_{\mathrm{L}} \quad$ Prandtl number for single-phase

$\mathrm{P} \quad$ Fluid pressure, $\mathrm{kg} \cdot \mathrm{m}^{-1} \cdot \mathrm{s}^{-2}$

$\mathrm{x} \quad$ Steam quality

$\left(r_{L V}\right) \quad$ Latent heat of vaporization, $\mathrm{J} \mathrm{kg}^{-1} \cdot \mathrm{K}^{-1}$

Tsat Saturation temperature, ${ }^{0} \mathrm{C}$

$\mathrm{T}_{\mathrm{P}} \quad$ Wall temperature, ${ }^{0} \mathrm{C}$

$\mathrm{N} \quad$ Numbers of experimental points.

V Steam speed, m.s s $^{-1}$

\section{Greek symbols}

$\alpha \quad$ two-phase heat transfer coefficient, $\mathrm{kg} \cdot \mathrm{m}^{-2} \cdot \mathrm{s}^{-3} \cdot \mathrm{K}^{-1}$

$\bar{\alpha} \quad$ Mean heat transfer coefficient, $\mathrm{kg} \cdot \mathrm{m}^{-2} \cdot \mathrm{s}^{-3} \cdot \mathrm{K}^{-1}$

$\delta \quad$ Thickness film, m

$\alpha_{\mathrm{T}} \quad$ Two-phase heat transfer coefficient, $\mathrm{kg} \cdot \mathrm{m}^{-2} \cdot \mathrm{s}^{-3} \cdot \mathrm{K}^{-1}$

$\theta$ med Inscript pipe angle,

$\mu \quad$ Dynamic viscosity, $\mathrm{kg} \cdot \mathrm{m}^{-1} \cdot \mathrm{s}^{-1}$

$\mu_{\mathrm{L}} \quad$ Liquid dynamic viscosity, $\mathrm{kg} \cdot \mathrm{m}^{-1} \cdot \mathrm{s}^{-1}$

$\mu_{\mathrm{V}} \quad$ Steam dynamic viscosity, $\mathrm{kg} . \mathrm{m}^{-1} \cdot \mathrm{s}^{-1}$

$\rho_{\mathrm{L}} \quad$ Density of liquid, $\mathrm{kg} \cdot \mathrm{m}^{-3}$

$\rho_{\mathrm{V}} \quad$ Density of vapor, $\mathrm{kg} \cdot \mathrm{m}^{-3}$

$\lambda \quad$ Fluid thermal conductivity, $\mathrm{W} \cdot \mathrm{m}^{-1} \cdot \mathrm{K}^{-1}$

$v_{\mathrm{L}} \quad$ Liquid kinematic viscosity, $\mathrm{m}^{2} . \mathrm{s}^{-1}$

$\Delta \mathrm{T} \quad$ Temperature difference across the condensate film, $\mathrm{K}$

\section{Subscripts}

Eq. Equation 